\title{
Valuation of the stabilization plan for the foot-and-mouth disease burial sites
}

\author{
Geonha Kim${ }^{1}$, Sung Soo Seol $^{+}$ \\ ${ }^{1}$ Department of Civil Engineering, Hannam University, Daejeon 306-791, Korea \\ ${ }^{2}$ Department of Economics, Hannam University, Daejeon 306-791, Korea
}

\begin{abstract}
About 4,500 mass burial sites of carcasses from the 2010/2011 outbreak of Foot-and-Mouth (FMD) disease in Korea show very slow stabilization speed, although more than 3 years have passed. Therefore, a plan is being considered to boost the speed of stabilization or removal. This is a study on the social value of the removal plan for 4,500 mass burial sites from the 2010/2011 outbreak of FMD in Korea. This valuation is based on the survey of 1,000 people living all over Korea. Korean people have a willingness to pay 101.2 billion Korean Won (about US $\$ 100$ million). This value is a large amount, but it is small compared to the cost of a FMD outbreak. The cost for the Korean government from 5 outbreaks since 2000 ranged from 28.8 billion Won to 3.2 trillion Won. These were the costs only paid by the Korean government. One estimate reported that there would be a total damage of 1.4 trillion Won, if FMD outbreak occurs in Jeju Islands, a small part of Korea. If burial sites have very slow stabilization speed and some hazardous contents, the social damage will exceed the removal cost.
\end{abstract}

Keywords: Foot-and-Mouth disease, Mass burial, Stabilization plan of burial site, Valuation

\section{Introduction}

\subsection{Outbreak of Foot-and-Mouth Disease in 2010/2011}

In Korea, the speed of spread of the 2010/2011 outbreak of foot-and-mouth disease (FMD) was $71.1 \mathrm{~km}$ per day [5]. The number of carcasses was 3.48 million: $95.4 \%$ were pigs, $4.3 \%$ cows and others. The number of burial sites was 4,583 . Gyunggi-do province was the top with $48.0 \%$ followed by Gyungsangbuk-do $24.5 \%$, Gangwon-do $10.3 \%$ and Choongcheongnam-do $8.9 \%$ etc. This outbreak put the nation into a National Emergency State [4].

Government ordered all carcasses to be buried into nearby places of outbreak because of the quick speed of spread and the danger of mobility. Nearly all the transportation at the time passed villages with high population density. Therefore, the Korean response at the time is characterized as 1) quick, 2) mass burial from thousands to hundreds of thousands in a site, 3) burial in the animal farm or near animal farms [13]. The burial sites had been protected for 3 years by the Epidemic Act.

The current status of burial sites is as follows: 1) The speed of stabilization of carcasses are very slow. 2) Most burial sites are expected to be reused or the signs of burial warning to be removed under diverse purposes. 3) If the sites are open, nobody is sure about the safety. 4) There are some legal problems in rented sites. Land owners want recovery of the sites [11, 12].

The slow stabilization is due to the burial methods: mass burial with calcium oxide covered with vinyl which permits no air and water pass through. Some sites excavated show nearly the same state with the time of burial with a lump of rigid carcasses like stone. Therefore, a research group funded by the government asserts the stabilization of burial sites [23]. Stabilization means the removal of the carcasses by diverse scientific methods such as chemical, biological or physical methods and the stabilization of land.

\subsection{Purpose and Method}

Then, how much do Korean people want to pay for this stabilization plan? The purpose of this paper is a measuring of the willingness to pay for this stabilization plan. Nobody is sure that the burial sites have no FMD viruses or other hazardous things under the same status with the time of burial. Further, some sites are expected to be open or broken. Korea has a possibility of mass outbreak of FMD again. Therefore, this study wants to figure out willingness to pay for getting rid of the danger.

Contingent valuation method (CVM) is a representative method to measure environmental goods [2, 6]. CVM has been developed 
especially by the US government during the 1980s and 1990s: The court order for measurement of non-use value in 1989, the incident of the Exxon Valdez in the nearby sea of Alaska in 1989 and the ensuring Oil Pollution Act of 1990 and the CVM report of the Blue Ribbon Panel led by 2 Nobel Prize winners funded by the US National Oceanographic and Atmospheric Administration [1]. Carson [3] counted over 7,500 CVM studies.

Even in Korea, more than 500 articles exist in the RISS (Research Information Sharing Service) DB of the Institute of Advanced Academic Information. In environmental areas, the value of flat mud [18, 19], facilities for city protection [22], facilities for port protection [24] and technologies for evaluation and management of ocean environment [20] are the samples.

CVM is a method for measuring the value of goods not existing in the world. Simply, the method sets a hypothetical market and asks for the willingness to pay (WTP). The method is a well-developed and standardized process used as the guideline of Arrow et al. [1] and used as the guideline of the Korea Development Institute (KDI) [14, 15] which is backed up by the Ministry of Planning and Budget [17]. The Korean government's guideline is used for the measurement of public investment.

\section{Materials and Methods}

\subsection{Model}

\subsubsection{Derivation of willingness to pay}

For the derivation of WTP from survey, we use the double-bounded model developed by Hanemann et al. [7].

Respondent $i$ reply for the 1st amount $A_{i}$ suggested as "yes" or "no". The 2nd amounts suggested for "yes" respondent and "no" respondent are denoted as $\mathrm{A}_{i}^{\mathrm{H}}$ and $\mathrm{A}_{i}^{\mathrm{L}}$. Like this, we can add more notations.

$$
\begin{aligned}
& I_{i}^{Y Y}=1\left(i^{\prime} \text { s answer is yes }- \text { yes }\right) \\
& I_{i}^{Y N}=1\left(i^{\prime} \text { s answer is yes }- \text { no }\right) \\
& I_{i}^{N Y}=1\left(i^{\prime} \text { s answer is no }- \text { yes }\right) \\
& I_{i}^{N N}=1\left(i^{\prime} \text { s answer is no }- \text { no }\right)
\end{aligned}
$$

$1(\cdot)$ is an indicator function which has 1 , if the condition satisfies, and 0 if not. For example, $I_{i}^{Y Y}$ is 1 , if the responses of respondent $i$ are "yes-yes", and 0 if not. If we suppose respondents who seek the maximization of utilities, we can set a log likelihood function based on respondent i's reply.

$$
\begin{aligned}
\operatorname{lnL}= & \sum_{i=1}^{n} I_{i}^{Y Y} \ln \left[1-G_{C}\left(A_{i}^{H}\right)\right]+I_{i}^{Y N} \ln \left[G_{C}\left(A_{i}^{H}\right)-G_{C}\left(A_{i}\right)\right] \\
& +I_{i}^{N Y} \ln \left[G_{C}\left(A_{i}^{H}\right)-G_{C}\left(A_{i}^{L}\right)\right]+I_{i}^{N Y} \ln \left[G_{C}\left(A_{i}\right)-G_{C}\left(A_{i}^{L}\right)\right] \\
& +I_{i}^{N N} \ln G_{C}\left(A_{i}^{L}\right)
\end{aligned}
$$

If we set $F_{\eta}(\cdot)$ as a logistically accumulated distribution function and combine with $\Delta=a-b A$, then the accumulated distribution function of WTP becomes (3).

$$
G_{C}(A)=\left[1+e^{(a-b A)}\right]^{-1}
$$

From Eq. (3), we can draw the average amount of WTP.

$$
C^{*}=a / b
$$

\subsubsection{Spike model}

Zero responses can be divided into two types: 0 and some amount between 0 and the suggested amount. As described later, our data also has zero response of $53.5 \%$, and this level of ratio is quite often observed in the survey for public goods [27]. Therefore, we used the Spike model to treat these zero responses [16, 26].

In the Spike model, the process is as follows: First, setting an accumulated distribution function of WTP as $G_{C}(\cdot ; \theta)$, and supposing it as logistic type, then we can draw the average amount of WTP.

If $=(a, b)$, accumulated distribution function of WTP is defined like Eq. (5).

$$
G_{C(A ; \theta)}= \begin{cases}{\left[1+e^{(a-b A)}\right]^{-1}} & \text { if } A>0 \\ {\left[1+e^{a}\right]^{-1}} & \text { if } A=0 \\ 0 & \text { if } A<0\end{cases}
$$

Therefore, log likelihood function of double-bounded Spike model is defined like eq. (6).

$$
\begin{aligned}
\operatorname{lnL}= & \left.\sum_{i=1}^{n} I_{i}^{Y Y} \ln \left[1=G_{C}\left(A_{i}^{H}\right)\right]+I_{i}^{Y N} \ln \left[G_{C\left(A_{i}{ }^{H}\right.}\right)-G_{C}\left(A_{i}\right)\right] \\
& +I_{i}^{N Y} \ln \left[G_{C}\left(A_{i}\right)-G_{C}\left(A_{i}^{L}\right)\right]+\left(I_{i}^{N Y}+I_{i}^{N N Y}\right) \\
& \ln \left[G_{C}\left(A_{i}^{L}\right)-G_{C}(0)\right]+I_{i}^{N N N} \ln G_{C}(0)
\end{aligned}
$$

The spike is defined as $1 / \ln \left(1+e^{a}\right)$ and it means the ratio of zero response. The average amount of WTP is estimated by Eq. (7).

$$
\overline{W T P}=\left(\frac{1}{b}\right) \ln \left[\left(1+e^{a}\right)\right]
$$

\subsection{Hypothetical Market and Survey}

\subsubsection{Goods and payment method}

Survey sheet is composed of 2 parts: respondent's recognition for FMD and burial, and the removal plan for the sites. In addition, 5 complementary cards are used for the explanation of each fact: reasons for mass burial, the end of legal protection for burial sites, location of burial sites, the danger of imprudent treatment of the sites, and the plan for removal and stabilization.

As for payment method, the amount of willingness to pay is set with 7 levels and payment method is by one time income tax. Following the Korean government guideline, we asked a question for reasons of zero response. In addition, we clearly stated the income tax will reduce real expense.

\subsubsection{Pre-test}

Following the guideline of NOAA (National Oceanic and Atmospheric Administration) and the Korean government, we pre-tested questions and payment level. The results were gathered at the workshop of the SAFE Research Group from 42 experts in the December of 2013, and from 20 spouses not related to the experts.

Twenty experts among 42 showed willingness to pay. However, the deviation between maximum and minimum WTP was too large, so we discarded upper and lower numbers following the recommendation of Hanemann and Kanninen [8] and Kannien [10]. As a result, we ended up with 7 levels of amount: 1,000, $3,000,5,000,7,000,10,000,15,000$, and 25,000. 


\subsubsection{Survey}

This survey was done basically under the guideline of the Korean government, so we used the sample distribution for surveys used by KDI who is the representative institute for government, and the company which KDI mainly asks to handle the surveys. Respondents were chosen as either head of household or spouse. Survey was done with 1,000 people on a face-to-face basis by visiting each house during January and February 2014. Survey sheets were tested by professional inspectors.

\section{Results and Discussion}

\subsection{Basic Statistics}

The demographics of respondents are shown in Table 1. The ratio between male and female is equivalent, and so is the ratio between

Table 1. Characteristics of Respondents

\begin{tabular}{|c|c|c|c|}
\hline \multicolumn{2}{|c|}{ Characteristics } & Family & Ratio (\%) \\
\hline \multirow{2}{*}{ Sex } & Male & 500 & 50.0 \\
\hline & Female & 500 & 50.0 \\
\hline \multirow{5}{*}{ Age } & $20 \mathrm{~s}$ & 43 & 4.3 \\
\hline & $30 \mathrm{~s}$ & 228 & 22.8 \\
\hline & $40 \mathrm{~s}$ & 356 & 35.6 \\
\hline & $50 \mathrm{~s}$ & 283 & 28.3 \\
\hline & $60 \mathrm{~s}$ & 90 & 9.0 \\
\hline \multirow{3}{*}{ Education } & Below middle school & 62 & 6.2 \\
\hline & High school & 425 & 42.5 \\
\hline & Over college & 513 & 51.3 \\
\hline \multirow{8}{*}{$\begin{array}{c}\text { Monthly } \\
\text { Income } \\
\text { after tax } \\
\text { (million Won) }\end{array}$} & Below 1 & 10 & 1.0 \\
\hline & $1-2$ & 90 & 9.0 \\
\hline & $2-3$ & 222 & 22.2 \\
\hline & $3-4$ & 224 & 22.4 \\
\hline & $4-5$ & 201 & 20.1 \\
\hline & $5-6$ & 154 & 15.4 \\
\hline & $6-8$ & 57 & 5.7 \\
\hline & Over 8 & 42 & 4.2 \\
\hline
\end{tabular}

"over college" and "below college". The "over college" means the respondents who are college or higher graduates, and the "below college" means the respondents who are high school or lower graduates.

\subsection{WTP}

The results from the double-bounded Spike model are seen in Table 3. Both of the coefficients of amount suggested and spike have a statistical reliability of $1 \%$.

The average WTP is 8,083.6 Won, and the 95\% confidence interval is 6,937-9,646 Won. Average WTP multiplied by the total number of families yields the total benefit of the plan. As of January 2014 , the total number of families is $18,457,628$. So, total benefit from the plan is 101.2 billion Won.

\subsection{Results with Multivariate Analysis}

Estimation results are influenced by the characteristics of respondents. Hence, we included two kinds of variables into the estimation. The first type consists of general characteristics such as sex, age, income, education, knowledge about FMD and mass burial. The second type is the dummy of the regions such as Gyunggi-do, Kyungsanbuk-do, Choongcheong-do and Gangwon-do.

The results with multivariate analysis are shown in Table 5. The key variables of amount suggested and the Spike value have statistical confidence of $1 \%$. Among the 1st type multivariate, income and knowledge about FMD show statistical confidence of $1 \%$ and the coefficients are positive. That means more income and more knowledge relate to willingness to pay more. Among dummy variables, Gyunggi-do dummy show 1\% statistical confidence and positive coefficient, and Gyungsangbuk-do dummy shows $5 \%$ confidence with negative coefficient. This means that the people of Gyunggi-do which have the largest sites want to pay more. The results of Gyungsangbuk-do are difficult to understand; Gyungsangbuk-do has many burial sites, but wants to pay less. So, we can ignore this case. Simply, the result from Gyunggi-do is reliable.

Table 2. WTP Distribution of Respondents

\begin{tabular}{ccccccccc}
\hline \multirow{2}{*}{$\begin{array}{c}\text { Amount suggested } \\
\text { (Won) }\end{array}$} & \multicolumn{2}{c}{ Y (yes) } & \multicolumn{2}{c}{ N (no) } & \multicolumn{2}{c}{ Total } \\
\cline { 2 - 7 } & Family & Ratio (\%) & Family & Ratio (\%) & Family & Ratio (\%) & Family & Ratio (\%) \\
\hline 1,000 & 94 & 28.9 & 9 & 6.4 & 40 & 7.5 & 143 \\
3,000 & 59 & 18.2 & 22 & 15.7 & 62 & 11.6 & 143 \\
5,000 & 51 & 15.7 & 17 & 12.1 & 75 & 14.0 & 143 \\
7,000 & 39 & 12.0 & 19 & 13.6 & 84 & 15.7 & 143 \\
10,000 & 36 & 11.1 & 16 & 11.4 & 91 & 17.0 & 143 \\
15,000 & 24 & 7.4 & 29 & 20.7 & 90 & 16.8 & 143 \\
25,000 & 22 & 6.8 & 28 & 20.0 & 93 & 17.4 & 14.3 \\
Total & 325 & 32.5 & 140 & 14.0 & 535 & 53.5 & 14.3 \\
\end{tabular}

WTP: willingness to pay.

The WTP distribution by amounts suggested is shown in Table 2. 53.5\% replied that they have no willingness to pay for the plan. This ratio is quite similar to $52.3 \%$ from pre-surveys. This ratio urged us to use the Spike model. 
Table 3. Average WTP

\begin{tabular}{cc}
\hline Contents & Coefficients (t-value) \\
\hline Constant & $-0.1747(-2.81)^{*}$ \\
Amounts & $-0.1112(-19.27)^{*}$ \\
Spike value & $0.5436(35.23)^{*}$ \\
Number of respondents & 1,000 \\
Log-likelihood & $-1,336.18$ \\
Wald Statistics (p-value) & $438.38(0.00)^{*}$ \\
Average WTP & $5,481.2$ Won $^{*}$ \\
Standard error & 0.33 \\
t-Statistics & 16.70 \\
99\% confidence interval & $4,740-6,418$ Won \\
95\% confidence interval & $4,893-6,198$ Won
\end{tabular}

WTP: willingness to pay.

* denotes $1 \%$ confidence level.

Confidence interval is calculated by Monte Carlo techniques with 5,000 iterations. Wald statistics was calculated under the hypothesis that all the parameters estimated were 0 .

Table 4. Total Benefit of the Plan

\begin{tabular}{ccc}
\hline Total family & $\begin{array}{c}\text { Average WTP estimate } \\
\text { (Won/family) }\end{array}$ & $\begin{array}{c}\text { Total benefit } \\
\text { (billion Won) }\end{array}$ \\
\hline $18,457,628$ & $5,481.2$ & 101.2 \\
\hline
\end{tabular}

As of January 2014. Statistical Bureau of Korea (www.kosis.kr).

Table 5. Estimation with Multivariate

\begin{tabular}{cc}
\hline Variables & Estimated coefficient (t-value) \\
\hline Constant & $-2.4481(-3.73)^{* *}$ \\
Amount suggested & $-0.1218(-19.51)^{* *}$ \\
Income & $0.1396(3.56)^{* *}$ \\
Sex & $-0.0322(-0.26)$ \\
Age & $0.0018(0.22)$ \\
Education & $0.1361(1.06)$ \\
Knowledge & $1.0786(3.12)^{* *}$ \\
Gyunggi-do & $1.2164(8.01)^{* *}$ \\
Chunhcheong-do & $-0.1609(-0.68)$ \\
Gyungsangbuk-do & $-0.7488(-2.43)^{*}$ \\
Gangwon-do & $0.5561(1.58)$ \\
Spike value & $0.5407(33.27)^{* *}$ \\
Number of families & 1,000 \\
log-likelihood & $-1,247.87$ \\
Wald Statistics (p-value) & $493.42(0.00)^{* *}$ \\
\hline
\end{tabular}

** and * means confidence level of $1 \%$ and $5 \%$ respectively.

Wald statistics was calculated under the hypothesis that all the parameters estimated were 0 .

\subsection{Cost for FMD and Burial Sites}

This is a study for the social value of the removal plan for 4,500 mass burial sites from the 2010/2011 outbreak of FMD in Korea. Korean people have willingness to pay 101.2 billion Korean Won (about US \$100 million). This value is a large amount, but it is small compared to the cost of FMD outbreak.
The cost to the Korean government from 5 outbreaks since 2000 ranged from 28.8 billion Won to 3.2 trillion Won. It costs 4.8 billion Won to 20.8 billion Won per outbreak, and 0.9 million to 135 million Won per carcass. The cost of the 2010/2011 outbreak was 20.8 billion Won per case and 0.91 million Won per carcass, because of the speed and the scope of regions [13]. These were the costs only paid by the Korean government, so the total costs from every outbreak is dramatically more.

Total damages including private damages were 8 billion Pounds for 4.2 billion carcasses with 2,030 cases in 2001 [25]. This can be exchanged to 5.9 billion Won per case, and 2.86 million Won per carcass. Pendell and Leatherman [21] estimated the damage of US \$1 billion, if a FMD outbreak occurs in 1 state with 5 regions. Kang et al. [9] estimated damages of 1.4 trillion Won, if a FMD outbreak occurs in Jeju Islands, a small part of Korea. If burial sites have very slow stabilization speed and some hazardous contents, the social damage will exceed the removal cost.

\section{Conclusions}

The sites from the 2010/2011 FMD outbreak show a very slow stabilization speed, although 3 years have passed. This is a study for measuring social value of the removal plan of FMD mass burial sites. The results are drawn from a nation-wide survey of 1,000 responses. We could have done new theoretical trials, but we just followed the guideline of the Korean government to show the public understanding of the plan. All public decisions are based on this guideline.

We use the double-bounded Spike model to draw willingness to pay. We expected many respondents had no real interest in this plan, since they had no direct relationship with burial sites. Even many respondents thought there are no problems in the sites. This fact led us into the selection of the Spike model to handle zero responses. However, the people in Gyunggi-do which has the largest burial sites think it is a problem. In addition, willingness to pay for the removal plan is related to income and knowledge level about FMD and mass burial sites. The more income and knowledge, the more willingness to pay for the plan.

Although this is a study for 4,500 burial sites of about 3.5 million carcasses, some sites show normal speed of stabilization. However, most sites where the SAFE Research Group of Hannam University visited are the sites with slow or no stabilization. Unfortunately, nobody knows the exact status of all the sites and the dangerousness of the sites.

\section{Acknowledgement}

This is a study funded by the Geo-Advanced Innovative Action (GAIA) Plan for soil and underwater pollution of the Ministry of Environment. We also acknowledge Professor Seung-Hoon Yoo of Seoul National University of Science and Technology for the comments for design and pre-survey of this study, and Sun-Young Park of Korea University for statistical handling, and CEO Geumsook Ryu of Research Prime for survey. 


\section{References}

1. Arrow K, Solow R, Portney PR, Leamer EE, Radner R, Schuman $\mathrm{H}$. Report of the NOAA Panel on contingent valuation. Federal Register. 1993.

2. Carson RT, et al. The value of preventing oil spill injuries to natural resources along California central coast. Natural Resources Damage Assessment Inc. 1996.

3. Carson RT. Contingent valuation: A comprehensive bibliography and history. Cheltenham; Edward Elgar. 2011.

4. Central Disaster Safety Headquarters. White paper of Central Disaster Safety Headquarters. Seoul; Ministry of Administration and Safety. 2001.

5. Choi SG, Song HH, Park GS. Analysis of foot-and-mouth disease diffusion velocity using network tool. Journal of the Korean society for geospatial information system. 2012;2:101-107.

6. Haab TC, Interis MG, Petrolia DR, Whitehead JC. From hopeless to curious? Thoughts on Hausman's "dubious to hopeless" critique of contingent valuation. Appl. Econ. Perspect. Policy. 2013;35:593-612.

7. Hanemann M, Loomis J, Kanninen B. Statistical efficiency of double-bounded dichotomous choice contingent valuation. Am. J. Agr. Econ. 1991;73:1255-1263.

8. Hanemann WM, Kanninen J. The statistical analysis of discrete-response CV data. In: Bateman IJ, Willis KG, eds. Valuing environmental preferences: Theory and practice of the contingent valuation method in the US, EU and developing countries. Oxford: Oxford University Press; 1999. p. 302-441.

9. Kang JY, Ko BH, Ko TH, Kang SJ. Analysis of the damages of the outbreak of foot-and-mouth disease in Jeju Island by scenario [Internet]. JDI focus. Vol. 110. JeJu: Jeju development institute; c2001. [cited 2014 Aug 15]. Available from: https://www.jdi.re.kr/contents/index.php?mid=0406\&job= detail\&seq $=498 \&$ gubun $=6$.

10. Kanninen BJ. Optimal experimental design for double-bounded dichotomous choice contingent valuation. Land Econ. 1993;69: 138-146.

11. Kim GH, Seol SS. Valuation of removal of FMD carcasses burial sites. In: 20th World Congress of Soil Science; 2014 June 8-13; Jeju.

12. Kim MH, Kim GH. Analysis of Environmental impacts using LCA for the carcass burial. Journal of Korean society for water environment. 2013;29:239-246.

13. Ko CR, Seol SS. Technology and policy measures for landfill sites of foot-and-mouth disease in Korea. Journal of Korea
Technology Innovation Society. 2013;16:978-1005.

14. Korea development institute. Guidelines for feasibility study. 5th ed. 2008.

15. Korea development institute public investment center. Guidelines for managing CVM applying projects. 2011.

16. Kristrom B. 1997. Spike models in contingent valuation. Am. J. Agr. Econ. 1997;79:1013-1023.

17. Ministry of planning and budget. 2012 Guidelines for feasibility study. 2012.

18. Park SY, Yoo SH, Ku SJ. Assessment of the non-market value of Boseong tidal flat. Ocean Policy Research 2011;26:47-73.

19. Park SY, Yoo SH, Kwak SJ. The conservation value of the Shinan Tidal Flat in Korea: a contingent valuation study. Int. Sust. Dev. World. 2013;20:54-62.

20. Park SY, Nam JH, Yoo SH. Economic feasibility analysis of developing marine environmental risk assessment and management technology. Journal of Korea technology innovation society. 2013;16:20-40.

21. Pendell D, Leatherman J Schroeder TC, Alward GS. The economic impacts of a foot-and-mouth disease outbreak: A regional analysis. Journal of agricultural and applied economics. 2007;39:19-33.

22. Ryu TC. A study on evaluating the economic value of urban facilities for damage prevention using CVM: In the case Gyeong-do fire station. Journal of Korea Society of Hazard Mitigation. 2013;13:177-184.

23. SAFE Research Group. Proceedings for managing technology for carcasses burial sites. In: SAFE research group workshop; 2013 Dec 10; Daejeon.

24. Seo IH, Shin SS. Estimation and comparison of benefits of disaster prevention facilities at the Masan Port with CVM and MD-FDA. Journal of Korea Port Economic Association. 2013;29: 289-323.

25. Thompson D, Muriel P, Russell D, et al. Economic costs of the foot and mouth disease outbreak in the United Kingdom in 2001. Rev. Sci. Tech. 2002;21:675-685.

26. Yoo SH, Kwak SJ. Using a spike model to deal with zero response data from double bounded dichotomous choice contingent valuation surveys. Appl. Econ. Lett. 2002;9:929-932.

27. Yoo SH, Kwak SJ, Kim TY. Modeling willingness to pay responses from dichotomous choice contingent valuation surveys with zero observations. Appl. Econ. 2001;33:523-529.

28. Yoo SH, Kim TY, Lee JK. Modeling zero response data from willingness to pay surveys: A semi-parametric estimation. Econ. Lett. 2001;71:191-196. 